\title{
Structural Analysis of Steel Structures under Fire Loading
}

C. Crosti

This paper focuses on the structural analysis of a steel structure under fire loading. In this framework, the objective is to highlight the importance of the right choice of analyses to develop, and of the finite element codes able to model the resistance and stiffness reduction due to the temperature increase. In addition, the evaluation of the structural collapse under fire load of a real building is considered, paying attention to the global behavior of the structure itself.

Keywords: Thermo-plastic material, non-linear analysis, steel structure, thermal buckling, bowing effect, structural collapse.

\section{Introduction}

This paper focuses on the structural analysis of a steel structure under fire loading. The use of an analysis with thermo-plastic materials, geometric nonlinearities and modeling of the fire action using parametric curves, allows a faithful evaluation of the effective behavior of steel structures subject to fire. In this context, once these two basic factors are clarified in isolated beam elements, they are applied to a steel structure under fire loading. This is done to highlight the importance of the right choice of analyses to develop, and of the finite element codes that are able to model the resistance and stiffness reduction due to the temperature increase. In addition, considering that for such a structure the evaluation of the structural collapse is very tricky and depends from many factors, a factor worth highlighting in a performance based approach is the global configuration of the structure itself.

\section{Definition of the generic model}

When assessing the performance resistance of steel elements subjected to fire, an important factor to take into account is the effect of temperature on the material in question. In the case of steel, in particular, the yield strength, the element ductility and its elastic proprieties, e.g., in Young's modulus, Poisson's Modulus and the proportional limit of stress, are strongly influenced by temperature increase. These characteristics therefore have to be used in the modeling, in order to achieve an accurate fire resistance assessment.

In this paper, the material used is a thermo-plastic type. The mechanical evolutive parameters taken into account in structures subjected to fire are:

- Young's Modulus, $E_{0}$;

- Effective Yield Stress, $s_{y}$, which represents the maximum capacity of the material;

- Coefficient of thermal expansion, $\alpha_{\mathrm{t}}$.

A simple proportional ratio between values at ambient temperature and values at a specific temperature [1] provides the evolution of these parameters as result of temperature increase.

Table 1 lists how much these parameters change with the temperature increase.

Table 1: Temperature effect on a thermo-plastic material

\begin{tabular}{|c|c|c|c|c|c|}
\hline$T\left({ }^{\circ} \mathrm{C}\right)$ & $E(\mathrm{~Pa})$ & $s_{y}(\mathrm{~Pa})$ & $E_{\mathrm{Pl}}(\mathrm{Pa})$ & $\alpha_{\mathrm{t}}\left({ }^{\circ} \mathrm{C}^{-1}\right)$ & $\mathrm{e}_{\mathrm{U}}$ \\
\hline 0 & $2.10 \mathrm{E}+11$ & $2.35 \mathrm{E}+08$ & $1.05 \mathrm{E}+10$ & $1.17 \mathrm{E}-05$ & 0.20 \\
\hline 20 & $2.10 \mathrm{E}+11$ & $2.35 \mathrm{E}+08$ & $1.05 \mathrm{E}+10$ & $1.17 \mathrm{E}-05$ & 0.20 \\
\hline 100 & $2.10 \mathrm{E}+11$ & $2.35 \mathrm{E}+08$ & $1.05 \mathrm{E}+10$ & $1.20 \mathrm{E}-05$ & 0.20 \\
\hline 200 & $1.89 \mathrm{E}+11$ & $2.35 \mathrm{E}+08$ & $9.45 \mathrm{E}+09$ & $1.23 \mathrm{E}-05$ & 0.20 \\
\hline 300 & $1.68 \mathrm{E}+11$ & $2.35 \mathrm{E}+08$ & $8.40 \mathrm{E}+09$ & $1.26 \mathrm{E}-05$ & 0.20 \\
\hline 400 & $1.47 \mathrm{E}+11$ & $2.35 \mathrm{E}+08$ & $7.35 \mathrm{E}+09$ & $1.30 \mathrm{E}-05$ & 0.20 \\
\hline 500 & $1.26 \mathrm{E}+11$ & $1.83 \mathrm{E}+08$ & $6.30 \mathrm{E}+09$ & $1.31 \mathrm{E}-05$ & 0.20 \\
\hline 600 & $6.51 \mathrm{E}+10$ & $1.10 \mathrm{E}+08$ & $3.26 \mathrm{E}+09$ & $1.34 \mathrm{E}-05$ & 0.20 \\
\hline 700 & $2.73 \mathrm{E}+10$ & $5.41 \mathrm{E}+07$ & $1.37 \mathrm{E}+09$ & $1.36 \mathrm{E}-05$ & 0.20 \\
\hline 800 & $1.89 \mathrm{E}+10$ & $2.59 \mathrm{E}+07$ & $9.45 \mathrm{E}+08$ & $1.38 \mathrm{E}-05$ & 0.20 \\
\hline 900 & $1.42 \mathrm{E}+10$ & $1.41 \mathrm{E}+07$ & $7.09 \mathrm{E}+08$ & $1.40 \mathrm{E}-05$ & 0.20 \\
\hline 1000 & $9.45 \mathrm{E}+09$ & $9.40 \mathrm{E}+06$ & $4.73 \mathrm{E}+08$ & $1.42 \mathrm{E}-05$ & 0.20 \\
\hline
\end{tabular}




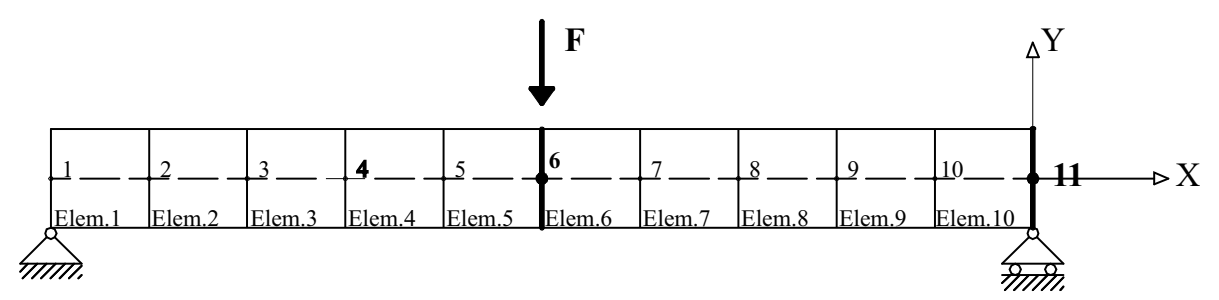

Fig. 1: Mesh of the element

A thermo-plastic material requires the use of Finite Element Code (FEC), which enables the correct implementation of these well-known evolutive parameters. Not all FECs allow the evaluation of thermo-plastic material behavior.

The calculation method finds numerical results by means of an iterative procedure: i.e., a procedure that predicts the updating of parameters with temperature increase. For solving the problem, it is therefore necessary to develop a nonlinear analysis, which is the only way to obtain a realistic representation of the problem.

In particular, geometric effects are very important for the study of structures under fire action. In fact, where these effects are not taken into consideration, buckling phenomena are not included in the analysis. This can be an important error, especially in the case of redundant structures. This aspect will be highlighted in the course of the paper.

In this paper, the fire action is applied to the element as a temperature curve, and the curve assigned is the parametric curve called ISO834 [1], which has a zero thermal gradient in the single finite element. This particular curve is used for identifying the class of fire resistance for a general structure as well as the evaluation of a general conventional assessment of fire resistance.

\section{Numerical analysis on isolated elements}

This section shows two basic examples related to steel elements subjected to fire action. These two examples enable the chosen model to be validated, evaluating how two different finite element codes, see Adina [2] and Strand [3], approach the fire resistance of steel structures.

These cases also enable us to deal with some typical behavior of a simple structure in which the collapse is due to loss of resistance and stiffness [4].

\subsection{Structural elements with unconstrained lateral expansion}

A three-meter-long simply supported beam has been considered, with a rectangular section of $0.3 \times 0.3$ meters. This beam is subjected to a constant vertical force $(F)$ at the midspan of $1410 \mathrm{kN}$ (Fig. 1).

By means of analyses accounting for the material and geometric nonlinearity, it is possible for example to evaluate how two finite element codes, see Adina [2] and Strand [3], manage to gather some of the phenomena that frequently emerge in steel elements subject to fire action.

One important consideration is the trend of the displacements in time, i.e., during the temperature increase. As an example, the trend of the vertical displacement of the node at the midspan of the beam is shown in Fig. 2.

Fig. 2 shows that after $400 \mathrm{sec}$, there are noteworthy displacements, due to the fact that that this time limit represents a critical time of fire resistance for the considered element. A similar consideration can be made observing the trend of the simple support horizontal displacement (Fig. 3), in which nevertheless it is possible to point out a phenomenon very frequent in structures subjected to fire.

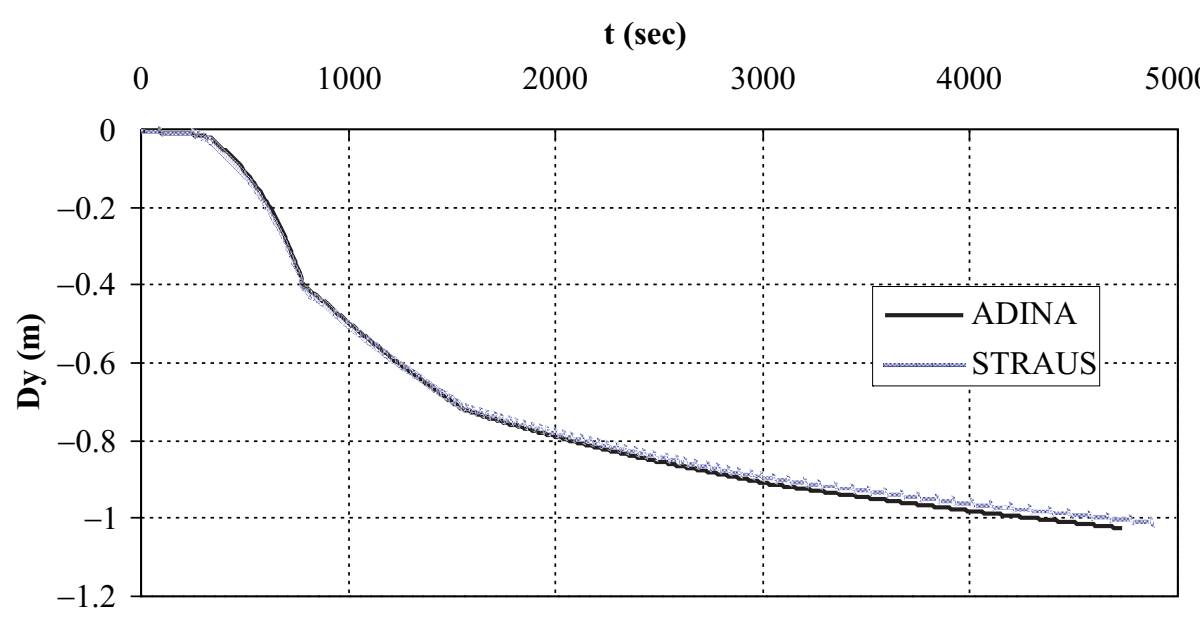

Fig. 2: Trend of vertical displacement in midspan, node no. 6 (Fig. 1) 


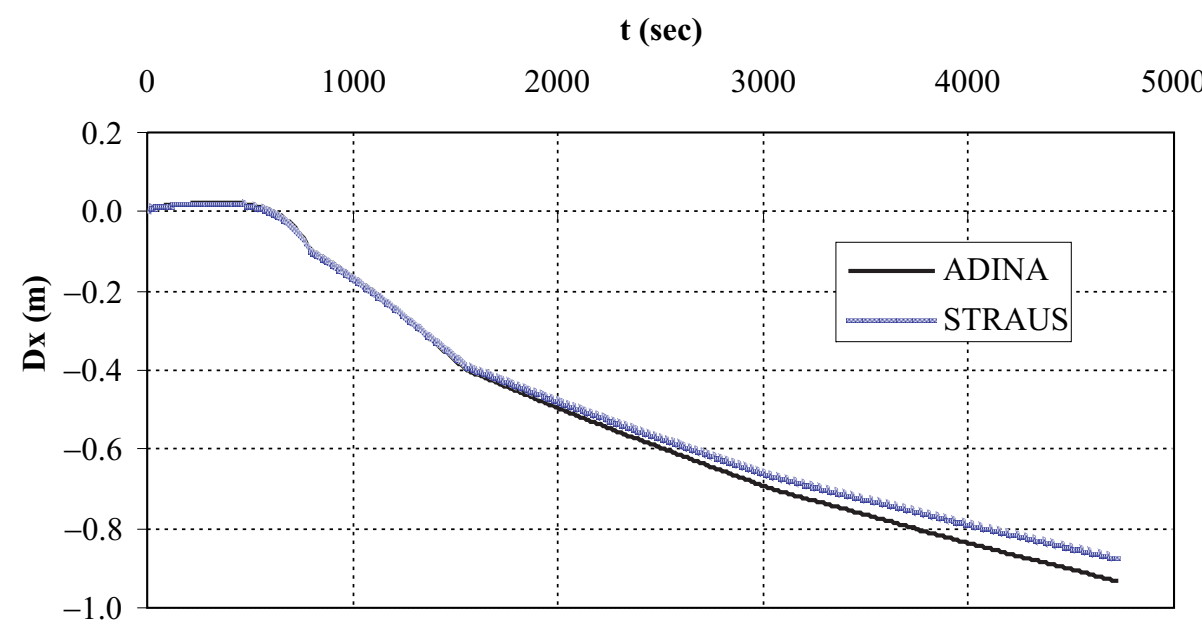

Fig. 3: Trend of horizontal displacement of node no. 11 (Fig. 1)

In fact, after an initial progressive lateral expansion, due to the initial temperature rise that generates positive displacements, the trend of the displacement is inverted. This inversion is because, after a certain time and due to the temperature rise, the beam is no longer able to support the applied load. This is due to the progressive temperature rise that leads to a noteworthy reduction in the load-bearing capacity of the structural element, thus leading to the progressive approaching of the external nodes, a phenomenon known in the literature as the bowing effect [5].

Therefore, referring to the horizontal node displacement of node no. 11 of the beam, it is simple to see how the coupling between material and geometric nonlinearity enables us to pick the progressive approaching of extreme nodes of the beam, when the temperature increases and the resistance and the stiffness decrease. This factor is perfectly pointed out in both codes used here.

\subsection{Structural element with constrained lateral expansion}

This paragraph analyzes the thermal buckling of an axially loaded beam, with both ends fixed against rotation. The beam considered here is 3 meters long, subjected to fire
(ISO834) [1] and to a lateral force $F=14 \mathrm{kN}$ at mid-length to simulate initial member imperfections. In this case, the beam is assumed to be restrained against lateral torsional buckling and so only in-plan overall buckling checks need to be made, this being the most critical case. The beam is of hypothetical square section in order to simplify the analysis. The restrained thermal expansion produces an indirect axial force that must be taken into account for a correct assessment of fire resistance, as shown in Fig. 4.

A square section of $0.1 \times 0.1$ meters has been considered. For this section, the analysis provides a solution only when the axial reaction produced by the thermal expansion is below the critical buckling load value, as shown in Fig. 4.

With an increase in element section, for example from $0.1 \times 0.1$ to $0.2 \times 0.2$ meters, the solution is stopped when the axial reaction curve crosses the yield development curve, as shown in Fig. 5. Above this yield load, there is an important fall in the critical buckling load, which becomes smaller than the yield load in such a way that the axial reaction cannot increase. In fact, with entrance into the plastic domain, Euler's equation, used to determine the critical buckling load in the elastic domain, can still be used as long as the Young's modulus is replaced by the Tangent Modulus value. This formula is known as Shanley's equation [6].

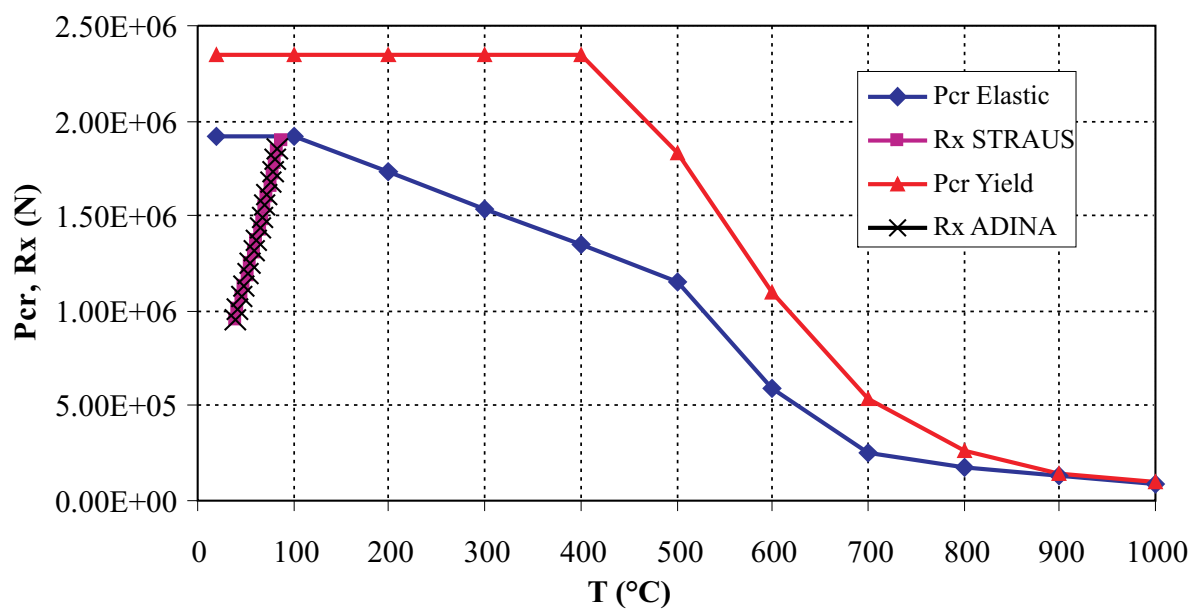

Fig. 4: Collapse for thermal buckling of an element with section $0.1 \times 0.1 \mathrm{~m}$ 


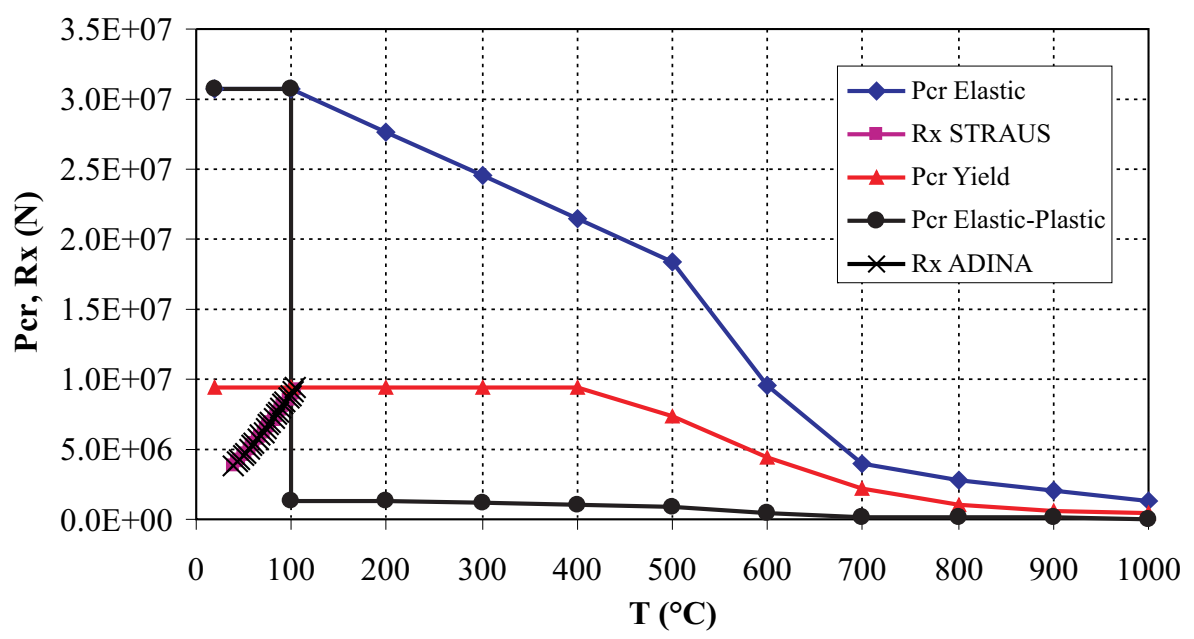

Fig. 5: Collapse for thermal buckling of an element with section $0.2 \times 0.2$ meters

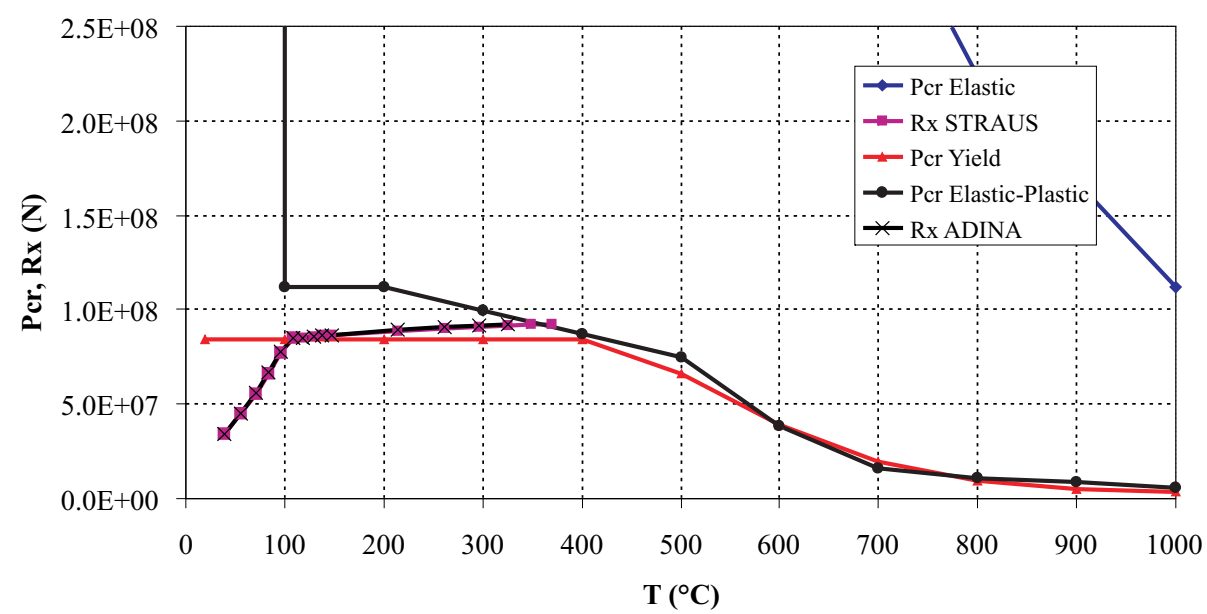

Fig. 6: Collapse for thermal buckling of an element with section $0.6 \times 0.6$ meters

By increasing the cross section from $0.1 \times 0.1$ to $0.2 \times 0.2$ meters, it can be observed that the solution is blocked in correspondence to the attainment of the yield strength (Fig. 5). When this is exceeded, a noteworthy decrease in the critical buckling strength is observed, which reaches a value lower than the yield strength. As a matter of fact, in the plastic field, the Euler formula, used for calculating the critical load in a linear elastic field, is still valid if the value of the elastic modulus $(E)$ is substituted by the tangent modulus (Shanley theory [6]). By increasing the cross section dimensions even more (up to $0.6 \times 0.6$ and $0.8 \times 0.8$ meters) it is possible to gather the post-yield strength, characterized by a noteworthy decrease in stiffness, denoted by the trend of the curves of the axial reaction (Fig. 6).

The results are synthesized in Table 2, where the critical temperature is also determined. For further considerations, the reader is referred to [4].

\section{Structural analysis of steel structures under fire}

This section investigates the structural behavior of a real steel structure. The objective of the analyses is, firstly, to high-

Table 2: Comparative results

\begin{tabular}{|c|c|c|c|}
\hline Case & Section $(\mathrm{m})$ & $T\left({ }^{\circ} \mathrm{C}\right)$ & Collapse for the achievement of: \\
\hline 1 & $0.1 \times 0.1$ & 77 & Elastic Buckling Load (Euler) \\
\hline 2 & $0.2 \times 0.2$ & 89.5 & Elastic-Plastic Buckling Load (Shanley) \\
\hline 3 & $0.6 \times 0.6$ & 331 & Elastic-Plastic Buckling Load (Shanley) \\
\hline 4 & $0.7 \times 0.7$ & 655 & Elastic-Plastic Buckling Load (Shanley) \\
\hline 5 & $0.8 \times 0.8$ & 1000 & No collapse \\
\hline
\end{tabular}


light some of the peculiar effects arising from the fire loading, and, secondly, to evaluate how changing the scenarios of the fire also changes the collapse of the structure. The analyses (implemented in commercial FEC Strand) account for the material and geometry nonlinearities, and are thus able to describe accurately the actual behavior of the structure. To carry out the fire resistance analyses, only vertical loads are applied to the structure, in accordance with the Italian Code [7] for structures subjected to fire action.

\subsection{Description of the structure and initial considerations}

The structure under inquiry is a single storey steel framed open deck car park, 32 meters long, 15 meters wide, with a maximum height of 3 meters. The deck consists in three rows of primary beams supporting seven rows of secondary beams, while appropriate steel braces contemplate the vertical elements. The FEM of the structure is shown in Fig. 7.

Due to the simplicity in the configuration of the structure and its particular utility, no comprehensive risk analysis has been performed at this stage. The fire scenarios were identified during the preliminary risk analysis process. Just four scenarios are taken into account, as shown in Fig. 8.
As stated above, the fire action is modeled by means of the ISO834 parametric curve applied directly to the elements involved in the fire.

Therefore, for example, in Scenario 1, this curve is applied to some secondary and principal beams and to the two columns of the central frame.

By means of non linear analyses, it was possible to include considerations of structural fire resistance, and also to figure out how some elements, such as the columns, are fundamental for the stability of the whole structure.

\subsection{Non-linear analysis results}

It is interesting to analyze the trend of the node at the top of the column involved in the fire in Scenario 1, to understand the global behavior of the structure.

As shown in Fig. 9, two phases can be clearly identified. In the first phase, the thermal expansion arouses positive displacement on the node.

Consequently and after around 600 seconds, a second phase takes place, characterized by an inversion to the trend of the displacement, which goes from a positive value to a negative value, due to the loss of resistance and stiffness of the column, which sags laterally. Fig. 9 shows the final de-

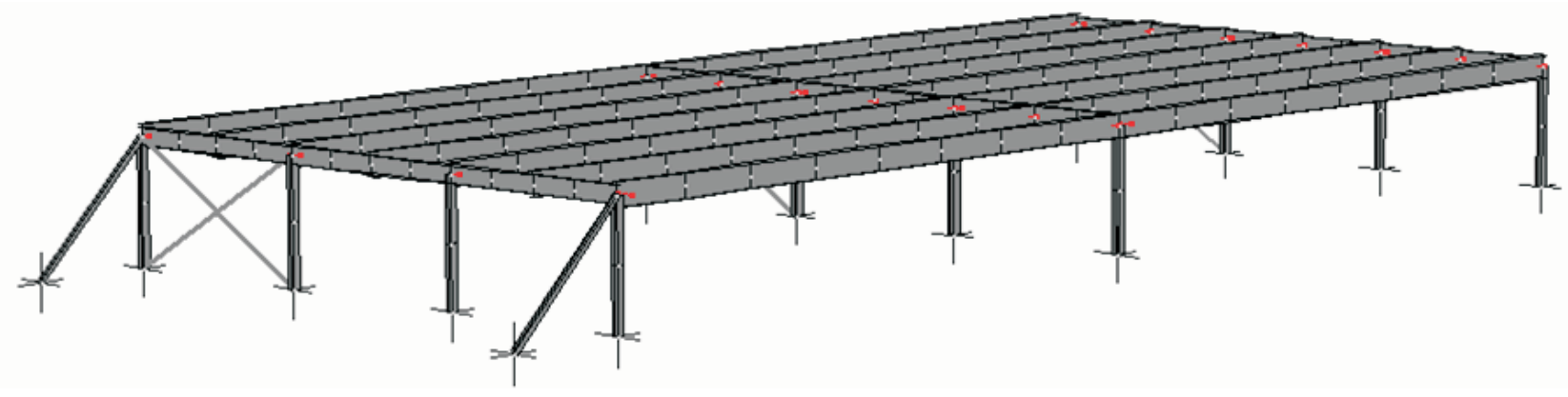

Fig. 7: Finite element model of the structure

\section{$\underline{\text { Scenario } n^{\circ} 1}$}

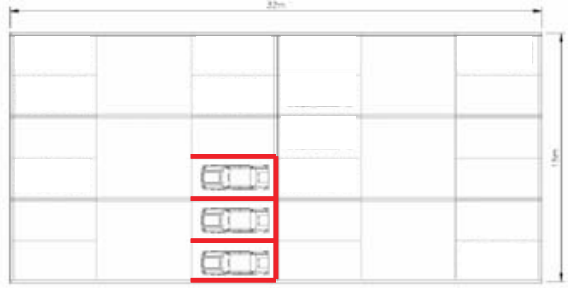

$\underline{\text { Scenario } n^{\circ} 3}$

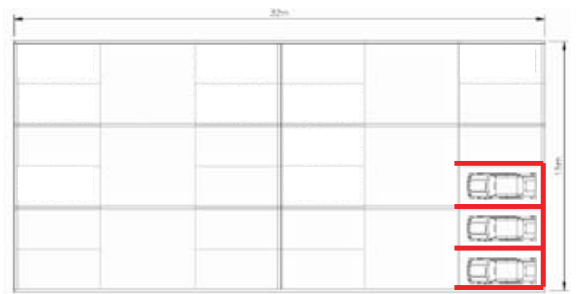

$\underline{\text { Scenario } n^{\circ} 2}$

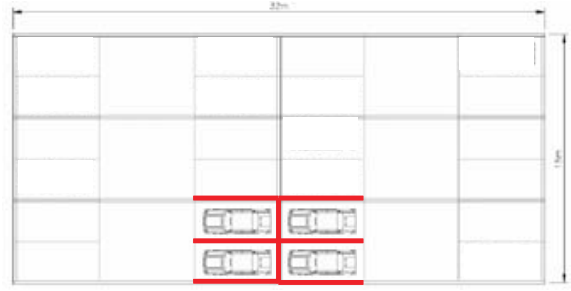

Scenario $n^{\circ} 4$

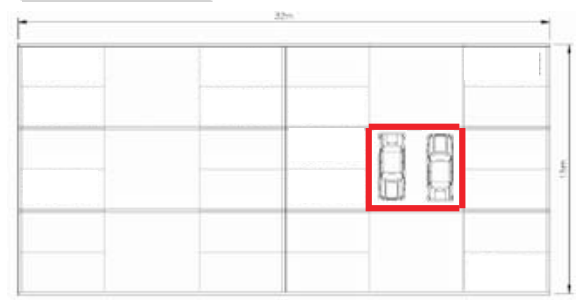

Fig. 8: Finite element model of the structure 


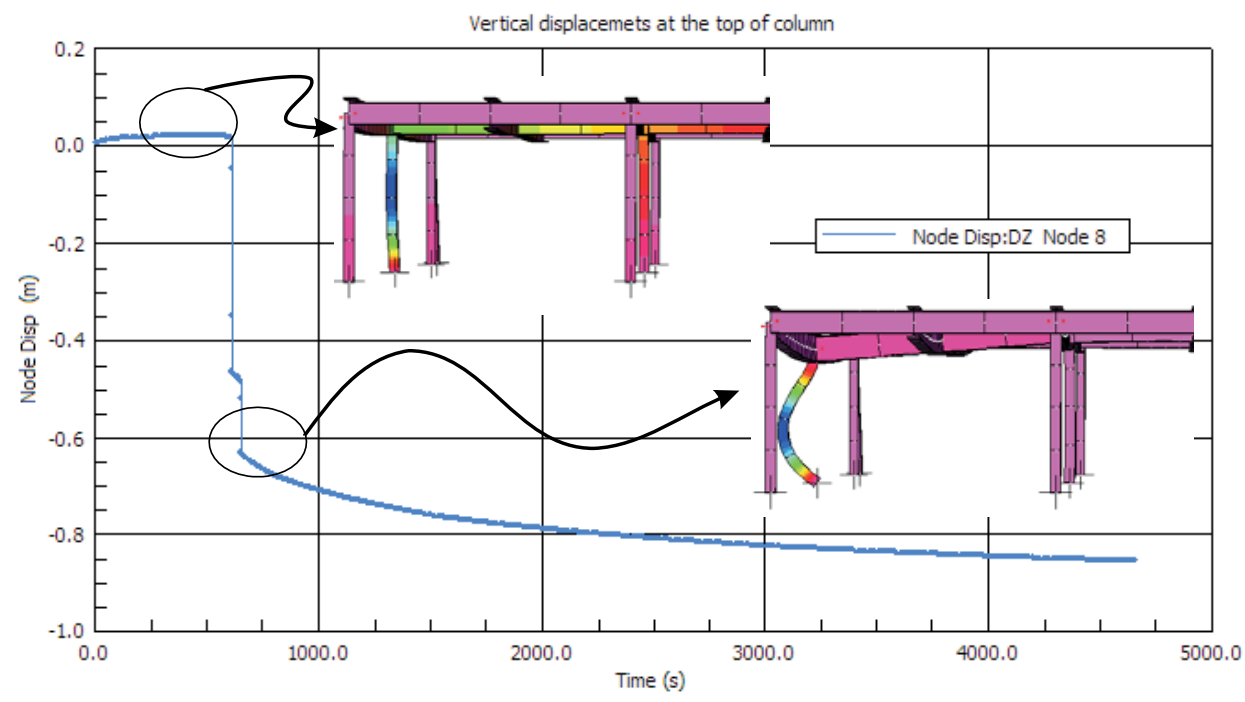

Fig. 9: Vertical displacements of the node at the top of the column

formed shape for the first scenario, where the columns are involved in the fire.

From the figure, we can evaluate how the application of fire to the columns leads to a critical state for the structure, due to the appearance of buckling phenomena. In fact, from the moment it loses its load bearing capacity, the column is no longer able to withstand the applied load and it sags towards its weak direction.

The situation in Scenario 4 is different. Here, the fire is applied only to some secondary beams and does not involve any columns; in Fig. 10, the zone involved by the fire is highlighted. From that scenario, it is also possible to evaluate how the structure seems to retain a good bearing capacity, even when there are large displacements on the secondary beams. This is because the damage is localized and does not compromise the stability of the whole structure. We can conclude that, in performance fire analyses, the global behavior of the struc- ture is more important than a study of the individual elements composing the structure. This leads to some considerations regarding the structural dependability of the facility [8], in terms of collapse resistance [9]. In fact, when a structure is redundant, there are many alternative load paths, large deformations can develop without a loss of its load bearing capacity, and structural failure must be accounted for in a different way. This phenomenon creates a sufficient reserve capacity to allow most of such structures to survive fires with reasonable structural damage.

Fig. 11 shows the final deformed shapes for the first three scenarios, in which there are columns involved in the fire.

Finally, Fig. 12 summarizes the deformed shape, the critical time and temperatures for each considered scenario, locating in Scenario 1 the worst case for the stability of this structure subjected to fire, having the lowest critical time and temperature of fire resistance.

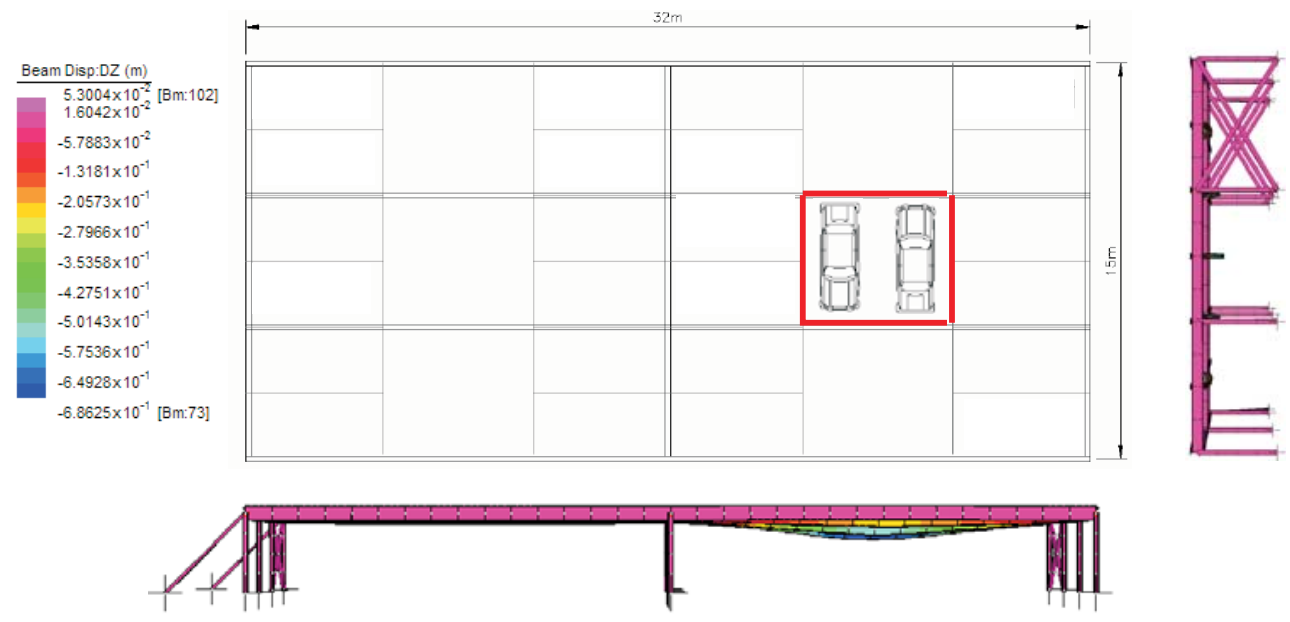

Fig. 10: Deformed shape for Scenario 4 


\section{Initial deformed shape}

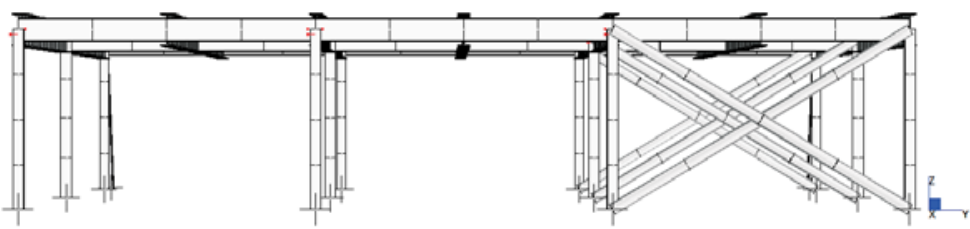

Initial deformed shape: Scenario 1

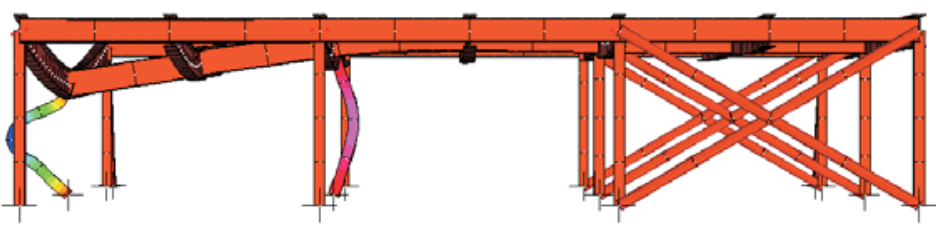

Initial deformed shape: Scenario 2

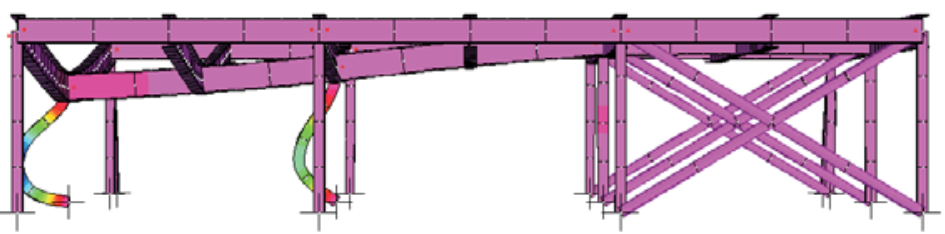

Initial deformed shape: Scenario 3

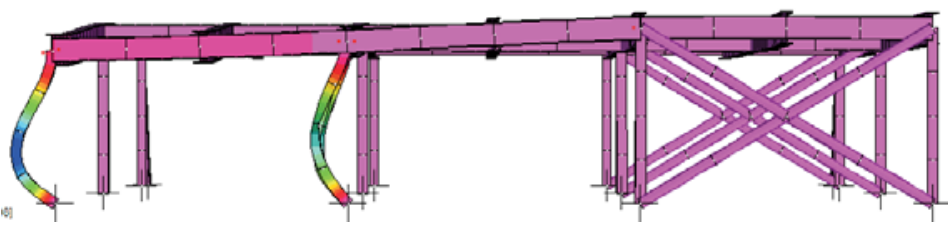

Fig. 11: Finite element model of the structure
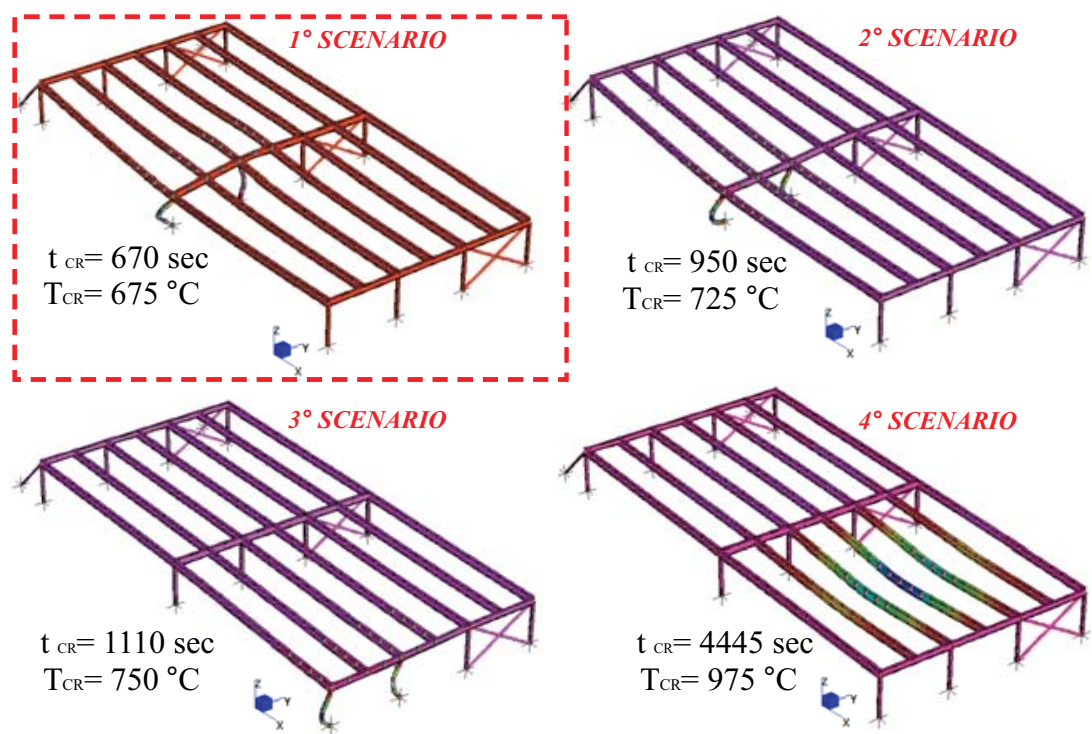

Fig. 12. Summary of critical states for the four scenarios considered here

\section{Conclusions}

This paper raises some considerations concerning the performance of steel structures under fire loading. For this purpose, the application of nonlinear analysis to the thermo-mechanic behavior of materials and to the structures as a whole, together with the appropriate fire modeling in appro- priate scenarios, come together to demonstrate and verify the performance of the structure in terms of resistance to fire during the design phase. All of this focuses on the importance of understanding the behavior of single elements while noting that the fundamental consideration in the structural collapse of a complex structure is the global behavior of the structure itself [10]. 


\section{Acknowledgments}

The author is grateful to her PhD advisor Professor Franco Bontempi, of the Sapienza, University of Rome, for his constant guidance in this research. Ing. Mauro Caciolai and Ing. Claudio De Angelis, of the Italian fire service, are also acknowledged for their fundamental opinions. Finally, special thanks are due to my colleagues Luisa Giuliani, Konstantinos Gkoumas and Francesco Petrini, who have spared their valuable time for discussions.

\section{References}

[1] Eurocode 3 - Design of steel structures, Part 1.2: Structural fire design, Commission of the European Communities, Brussels, 1993.

[2] Adina, www.adina.com

[3] Strand, www.strand7.com

[4] Crosti, C., Bontempi, F.: Performance Assessment of Steel Structures Subject to Fire Action. Proceedings of the CST2008 \& ECT2008 Conferences, Athens, 2-5 September 2008 .

[5] Usmani, A. S., Rotter, J. M.: Fundamental Principles of Structural behavior under Thermal Effects. First International Workshop on Structures in Fire, Copenhagen, Denmark, 2000.
[6] Shanley, F. R.: Inelastic Column Theory, Journal of the Aeronautical Sciences, Vol. 14 (1947), No. 5, p. 261-268.

[7] D.M. 14/09/2005 - Norme Tecniche per le Costruzioni (in Italian), Ministry of Infrastructures and Transportation, Italy, 2005.

[8] Bontempi, F., Giuliani, L., Gkoumas, K.: Handling the Exceptions: Dependability of Systems and Structural Robustness, in Recent Developments in Structural Engineering. Mechanics and Computation, Alphose Zingoni (Ed.), Millpress, Rotterdam, 2007.

[9] Starossek, U., Wolff, M.: Design of Collapse Resistant Structures. Workshop on Robustness of Structures (JCSS and IABSE), November 28-29, 2005.

[10] Crosti, C., Bontempi, F.: Safety Performance Evaluation of Steel Structure under Fire Action by Means of Nonlinear Analysis. Proceedings of the CST2008 \& ECT2008 Conferences, Athens, 2-5 September 2008.

Chiara Crosti

e-mail: chiara.crosti@uniroma1.it

Sapienza - University of Rome School of Engineering, Rome, Italy 